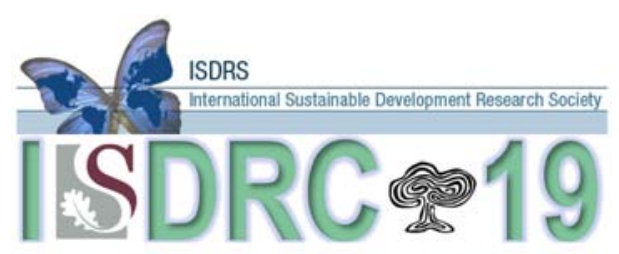

Just Transitions: A global perspective

www.isdrc19.co.za

\title{
Just Transitions and a Contested Space: Antarctica and the Global South
}

\author{
Jane Verbitsky \\ AUT University; jane.verbitsky@aut.ac.nz
}

\begin{abstract}
This paper suggests that Global South states should prioritize Antarctica as a core transnational issue because of the potential rewards it offers in terms of opportunities for advancing their common political and development agendas. Global South states are significantly underrepresented in Antarctic Treaty System (ATS) governance. Consequently, they have minimal input into the shaping and direction of ATS decisionmaking on issues such as Antarctic bio-prospecting, fishing and tourism or, critically, into debates about the role and status of Antarctica in the international system. Nevertheless, Antarctica represents opportunities for Global South (GS) states to realize shared cosmopolitan democracy and environmental justice goals. While contemporary media coverage of the southernmost continent has focussed on its vital role in global climate change, Antarctica is also important for GS states because it is a contested, nonsovereign area without a clearly defined status or future (international or global commons, Common Heritage of Mankind, global wilderness?) that could be integral to their future development. The paper advocates the benefits for developing states of participating in Antarctic governance, drawing on theories of cosmopolitan democracy and environmental justice to demonstrate that these can be utilised by GS states to reinvigorate and move forward international debates about the role, status and future of Antarctica and provide a central place for GS states in that future. Additionally, these theories can be practically applied to GS development goals in respect to issues such as the management of Antarctica, access to sustainable resources, and benefit sharing from Antarctic resource extraction.
\end{abstract}

Keywords: Antarctica; Global South; environment; justice; development; democracy

\section{Introduction}

Over the last decade climate change has become the dominant theme of global environmental news, and it is in this context that Antarctica has figured most prominently in media coverage. Hence, stories featuring Antarctica have centred on the continent's central role in the global eco-system, focusing particularly on changing sea ice patterns, shrinking of the polar ice cap, and the invidious impacts on native flora, fauna and wildlife derived from changing environmental conditions.

Yet Antarctica deserves closer attention for other, equally salient reasons. The world's fifth largest continent - the coldest, driest, windiest, and most remote place on earth - is also a non-sovereign, contested space containing natural resources that are increasingly scarce in other parts of the globe. (Berkman, 2002: pp.163-191, 211). It is also a continent with an uncertain future, characterized by contradictions. While the Antarctic Treaty of 1959 unequivocally declared the continent to be a non-militarized, nuclear-free area, the political status of the continent in 2013 remains unresolved. It is routinely described in scholarly texts as an international or global commons (Vogler 1995, p.8; Buck 1998, p.6), although each appellation carries a different meaning, and attempts have also 
been made to claim that it is part of the Common Heritage of Mankind. It is administered through a multilateral, condominium governance system, the Antarctic Treaty System (ATS) that stresses its stewardship of the continent on behalf of the global community, despite only 50 states being signatories to the Antarctic Treaty. (Antarctic Treaty Secretariat, 2013) A campaign in the 1980s to make Antarctica a World Park failed and, although Article 2 of the Protocol on Environmental Protection to the Antarctic Treaty, 1991 describes the continent as a "natural reserve" and Article 3(1) refers to its "wilderness" value, the silent continent is increasingly subject to globalization and to commercialization pressures that threaten the integrity of the natural reserve and wilderness concepts. Further, despite the assertion in the preamble to the Antarctic Treaty that Antarctica should never become "the scene or object of international discord", the national interests of signatory states and non-extinguishment of pre-Treaty claims to the continent mean that sovereignty is always a live issue in any long-term consideration of Antarctica's future. (Dodds, 2011)

It is, however, these contradictions and uncertainties about Antarctica's status and future that present opportunities for Global South states to promote shared interests in the continent and to use those interests to help springboard their common political and developmental goals. This paper examines the reasons why Global South decisionmakers should become more engaged with Antarctica and the ATS, and how they can utilise environmental justice and cosmopolitan democracy theories to help advance a future for Antarctica in which they are integrally involved. It advocates for participation by Global South states in the ATS and its governance of the continent to ensure that the promise in the preamble to the Antarctic Treaty that Antarctica shall be used for "the progress of all mankind" will be fulfilled to the greatest extent possible.

\section{The Global South and pre-Treaty Antarctica}

The countries of the Global South are the poorest and least developed on earth. Although the term 'Global South' is a rubric that is applied to an extraordinarily diverse group of countries that, in many respects, differ significantly from each other, they are marked by the commonality of their deprivation and poverty relative to the states that comprise the Global North. One way of identifying the countries of the Global South is through the Human Development Index (HDI) published in the United Nations annual Human Development Report. The HDI aggregates three dimensions - health, education and income - into a summary measure using country level information that ranks states in one of four categories: very high human development; high human development; medium human development; and low human development. As a crude division, those states that fall into the medium and low human development categories (93 of the 187 states captured in the $2011 \mathrm{HDI}$ ) can be regarded as comprising the Global South (GS). The 46 states in the medium human development category are the more developed of the GS group, while the 45 states making up the low human development category are the least developed and poorest of the group. (UNDP 2011, pp.17-20)

The common political and developmental goals of the GS group are represented in the 2000 United Nations General Assembly resolution 55/2, United Nations Millennium Declaration. The Millennium Development Goals (MDG) consist of twenty-nine comprehensive sets of objectives to be achieved by 2015. These objectives are derived from six "fundamental values" considered "essential to international relations in the twenty-first century": freedom; equality; solidarity; tolerance; respect for nature; and shared responsibility. (UNGAR 2000, p.2) The MDGs cover a wide range of goals from poverty eradication, protecting the vulnerable, and meeting the special needs of Africa through to human rights, democracy, good governance and disarmament. They are interrelated and mutually-reinforcing in that together their accomplishment would help realise the "principles of human dignity, equality and equity at the global level" that world leaders 
collectively pledged to achieve, and contribute to "an overall commitment to just and democratic societies for development." (UNGAR 2010, p.1)

GS states have had little involvement with Antarctica and the ATS. Indeed, of the 50 states that are signatories to the Antarctic Treaty, only six of them (China, India, South Africa, Guatemala, Pakistan and Papua New Guinea) are included in the GS group. Moreover, of those six, only three (China, India and South Africa) are Consultative Parties - that is, part of the elite group of twenty-eight states that are entitled to participate and vote at the annual Antarctic Treaty Consultative Meetings (ATCMs) that regulate the Antarctic governance system. It is the Consultative Parties who are the decision-makers for the ATS and, consequently, the arbiters of Antarctica's future.

That GS states have had little involvement with Antarctica and the ATS is attributable to their lack of autonomy or agency during key periods of international engagement with the continent. It was during the latter part of the $19^{\text {th }}$ century that the 'heroic' era of national expeditions to Antarctica began, an era coinciding with imperial colonization and the absorption of territories into European empires. (Chaturvedi 1996) Over a period of three and a half decades, seven states - Argentina (1943), Australia, (1933) Chile (1940), France (1924), New Zealand (1923), Norway (1939), and the United Kingdom (1908 \& 1917) - laid claim to 80 percent of the continent. Three of the claimed areas, those of Argentina, Chile and the United Kingdom, overlap and tensions between these claimant states threatened to spill into armed conflict in the late 1940s. (Grob 2007, pp.466-467) A move by the United Kingdom to take the matter to international arbitration in 1955 failed when Chile and Argentina refused to recognise the jurisdiction of the International Court of Justice. (Dodds 2012, p. 55)

Antarctic politics were changed fundamentally in the late 1950s by the experience of the International Geophysical Year (IGY) of 1957-58. During the IGY, states around the world participated in cooperative international scientific activities, including twelve countries that worked together on Antarctic projects. The success of the IGY led the United States to invite the other eleven countries involved in the Antarctic projects to Washington in 1959 to create a multilateral treaty using the IGY's cooperative scientific internationalism as the basis for a system of governance. The outcome of the negotiations and deliberations was the Antarctic Treaty of 1959, in force from 1961. The Antarctic Treaty has become the framework of governance and administration for the continent, with scientific knowledge acting as "an important currency in the realm of governance". (Elzinga 2013, p.197)

\section{Antarctica as a contested space}

Antarctica has been a contested space since at least the fifteenth century. As Scott (2011, p.58) notes, Antarctica has been subject to three waves of imperialism, two of them pre-Treaty, with the Antarctic Treaty itself "an act of imperialism on the part of the US." Whalers and sealers vied with each other for Antarctica's resources under contending flags, while nationalism and colonial expansionism fuelled the campaigns of early explorers and polar expeditions. The placement of national research stations, which dotted the continent from the 1940s, can also be seen as "a surrogate expression of colonialism". (Elzinga 2013, p.197)

Antarctica's future has, at different times in the $20^{\text {th }}$ century, been debated within the international community. Political internationalism of the continent was mooted by different individuals and groups from 1910-1946. (Bulkeley 2010, p.9) After the formation of the United Nations (UN) in 1945, though, most proposals, including those by the US, India and New Zealand, envisaged the UN as having a trusteeship, or similar, role for the continent. (Beck 1986, pp.272-273) 
The most sustained and public discussion, however, took place in the UN General Assembly when the issue of GS concerns over Antarctica exploded into international consciousness in the 1980s. A campaign spearheaded by Malaysia brought to public attention the dissatisfaction and grievance felt by many GS states about the Antarctic Treaty System. The campaign began in earnest following the conclusion of the United Nations Convention on the Law of the Sea (UNCLOS), 1982. It was fuelled, in part, by the successful inclusion of Article 86's description of The Area (that part of the seabed beyond national jurisdiction) as part of the Common Heritage of Mankind ( $\mathrm{CHM}$ ). It was also motivated by anticipation that mining would shortly begin in the continent, and that the financial rewards generated from mining would exclusively devolve to ATS members. In September of that year the Malaysian president, Dr Mahatir, called in the UN for a meeting about Antarctica's "uninhabited lands" and the "neo-colonial" Antarctic Treaty. (Triggs 1987, p.229) By the following year Antarctica had been placed on the agenda of the General Assembly and, in 1984, the Secretary General was asked to make a study on Antarctica and report back to the Assembly.

The debate over Antarctica that ensued in the Assembly focused primarily on the part of the GS states on the perceived ring-fencing of Antarctica by the ATS, and the secretive, unaccountable and "privileged" nature of the ATS's "rich man's club", the Consultative Parties group. (Beck 1986, pp.183-184) One of the key criticisms was about the difficulties faced by signatory states in trying to gain entry to this decision-making group. That distinction is based on the Article IX(2) requirement that states acceding to the Treaty are only entitled to participate in ATCM decision-making

during such time as that Contracting Party demonstrates its interest in Antarctica by conducting substantial scientific research activity there, such as the establishment of a scientific station or the despatch of a scientific expedition.

That requirement was castigated by GS states as financially onerous and exclusionary, and a continuing barrier to their participation in the ATS. Ire was also raised by the inclusion of apartheid South Africa among the decision-making elite, an inclusion that for GS states illustrated the neo-colonial nature of the ATS and its undemocratic, unequal structures. By contrast, Contracting Parties defended staunchly the ATS, their positions in the decision-making group, and rejected completely the push by GS states to label Antarctica a $\mathrm{CHM}$ and thus subject to equitable access and resource extraction benefitsharing along the same lines as the scheme set up in Part IV of UNCLOS. Rejoinders to GS criticisms by them included assertions that GS states were inexperienced and illinformed in Antarctic matters, only interested in mining riches, simply attempting to embarrass former colonial states and the US, and unable to contribute to Antarctic scientific programmes. (Beck 1986, pp.183-206; Triggs 1987, pp.230-233)

Over a series of years the two groups clashed in the Assembly as the "Question of Antarctica" reappeared annually on the agenda. It was not until concessions were eventually made by the Consultative Parties (greater information-sharing about Antarctic affairs, flexible interpretation of the Article IX(2) criterion to fast-track China and India's applications for Consultative Party status, and the creation of a mining ban in Antarctica for fifty years) that the criticisms finally began to die away. Nonetheless, the practice of reporting on the "Question of Antarctica" in the UN was finally discontinued only in 2006.

\section{The Global South, Antarctica and the Antarctic Treaty System in the new millennium: Issues and challenges}

The last two decades have brought significant changes to Antarctica. Commercialisation and commodification of Antarctica and Antarctic resources has become increasingly 
evident. For instance, tourism numbers have increased sharply over the last twenty years, and the industry now brings thousands of people each year to the continent. Tourism has, in fact, become the single largest human activity on the continent with 22,122 landed tourists visiting Antarctica during the 2011-2012 austral summer, and continuing growth in numbers predicted. (IAATO 2012) Fishing activity has also expanded during the same time period. As northern oceans become over-fished and fish-stocks dwindle, fishing fleets have moved further southwards into Antarctic waters and Illegal, Unauthorised and Unregulated (IUU) fishing has increased exponentially. That this situation has serious environmental and economic consequences is borne home by estimates that

illegal and unregulated fishing causes annual financial losses of up to $\$ 23.5$ billion worldwide and accounts for up to 20 percent of all of the wild marine fish caught globally. (Pew Charitable Trusts 2013)

The ATS itself also faces challenges. Effectively, there has been institutional stasis since 1991 when the Protocol on Environmental Protection to the Antarctic Treaty (PEPAT) was created. (Hemmings 2007, p.185) There is only a skeletal regulatory framework for Antarctic tourism, despite the evident need for more careful monitoring and regulation of the industry and tourism practices in and around the continent (Verbitsky, 2012). Criticism has also focused on the harmful effects of human interaction with the Antarctic environment and, in that context, the Environmental Impact Assessment procedures built into PEPAT have been found wanting by commentators. As Hemmings (2007, p.189) has stated, "Antarctica's thin international governance regime appears under pressure and commercial competition is beginning to displace scientific cooperation as the driver of policy in the region." Whether the ATS can muster the collective political will to reverse the trend remains a moot question.

Sovereign claims to Antarctica are 'frozen' under Article IV of the Antarctic Treaty which places all such claims in abeyance for the duration of the Treaty. Nevertheless, sovereignty matters have been reinvigorated by the issue of continental shelves recognition. This issue derives from Article 76 of UNCLOS. The convention includes provisions in Article 76 for coastal states to be able to extend their Exclusive Economic Zone maximum entitlement of 200 nautical miles up to another 150 nautical miles by submitting applications supporting recognition of national continental shelves to the Commission on the Limits of the Continental Shelf for decision. The extension of continental shelves has direct relevance for Consultative Party coastal states in proximity to Antarctica, and raises serious issues about the presence of two separate, but overlapping, legal regimes in the area south of $60^{\circ}$ South. (Rothwell \& Scott, 2007, pp.1316; Rayfuse 2008)

Bioprospecting, "the search for, extraction and testing of chemical compounds and genetic material from living organisms" and a "spin off from increasingly sophisticated Antarctic scientific research and its revelations about biodiversity in the region", is yet another issue with relevance to commercialisation and sovereignty issues. (Hemmings 2007, p.181) The economic reward from patents and products developed from bioprospecting is potentially enormous. It is obviously an issue of interest to many states outside the ATS, not least because of the comparisons that can be drawn with access to and benefit sharing from resource extraction in The Area under UNCLOS. Yet bioprospecting is already occurring in Antarctica without "clarity about jurisdictional scope, regulatory status, access arrangements, environmental implications, commercial use of material and information and benefit-sharing." (Jabour 2013, p.242) Like tourism and IUU fishing, Antarctic bioprospecting is in dire need of ATS intervention and regulation, and would certainly be a prime target for any GS internal reform efforts. 


\section{Cosmopolitan Democracy and Environmental Justice theories}

Just as the last three decades have brought change and presented new challenges to Antarctica and the ATS, so, too, has transformation occurred in global politics. The ending of the Cold War and movement into a New World Order has been characterized by globalization and democratization. While advocates were premature in pronouncing the end of history and 'victory' of democracy, nevertheless there have been significant developments internationally in terms of greater interconnections between states, the growth of civil society, and the expanding influence of democratic practices. As we have moved further into the 'century of the environment', there has also been increased consciousness of the need to commonly address trans-boundary environmental issues and problems. These different elements have helped spark interest in prospects for global governance, democracy beyond borders, sustainable development, and new means of addressing inequalities and achieving social justice. In this context, theories of cosmopolitan democracy and environmental justice offer real possibilities for beneficial change to Global South states, particularly when applied to Antarctica and the ATS.

\subsection{Cosmopolitan Democracy}

Cosmopolitan democracy has been described as "a basis for combining the democratization of global governance with the pursuit of social justice" (McGrew 2008, p. 31). As Heywood (2012, p.320) has noted, it "emerged out of debates about the nature and future direction of global governance", and is particularly concerned with "a lack of democratic participation and accountability" in the emerging system of global governance. Archibugi (2003, p.261) sums up the "political project of cosmopolitan democracy" thus:

it is the attempt to reconcile the phenomenon of globalization with the successes of democracy. It sets out from an acknowledgement of the fact that state-based democracy, the only form we know today, risks being hollowed out by the processes of globalization. At the same time, the dynamics of globalization have to be regulated, and carrying this out exclusively at state level is difficult, sometimes impossible.

Cosmopolitan democracy focuses on the global governance system, the place of states within that system, and what it sees as the democratic deficit both within global governance provision and between states. The democratic deficit starts with the idea that the Westphalian state system correlating sovereignty, autonomy and authority with the boundaries of territorial states has been steadily eroded. The advent of layers of transnational institutions and agreements, and the plurality and networks of non-state actors at the international level have permeated state sovereignty and weakened the ability of the state to act as an autonomous agent in global politics. Thus, there are limits faced by states in managing complex problems (such as climate change, desertification and oceans pollution) and providing for the public interest and civic participation. The proponents of the democratic deficit thus assert that the "idea of a democratic order can no longer be simply defended as an idea suitable to a particular closed political community or nation-state" (Held 1998, p.22).

Cosmopolitan democracy also takes up the idea of political community as being composed of transnational citizens who are affected at different levels (local, regional, global) by the actions of political elites. What this implies is that cosmopolitan citizens, members of different societies, come together to "influence decisions that have global influence". (Linklater 2008, p.551) In its simplest form, according to Held (2007, p.248), the principle of equivalence between decision-makers and decision-takers "suggests that those who are significantly affected by a global good or bad should have a say in its provision or regulation." This means the recognition that subnational and transnational 
citizenships "supplement existing forms of national citizenship" (Linklater 1998, p.114), and the requirement that in a "world of overlapping communities of fate" (Held 1998, p.24) notions of consent, participation and legitimacy need to be re-negotiated within new political institutions to achieve a representative and accountable system. Thus, what is needed is to have a range of fora, not just global spaces - although this is an essential element in an increasingly transnational world - but also local and regional ones, where the decision-makers are held to account by the decision-takers.

How, then, to achieve the vision of cosmopolitan democracy? For the best-known exponent of cosmopolitan democracy, David Held, the transformation that needs to occur is the entrenchment and development of "political institutions at regional and global levels as a necessary supplement to those at the level of the state" (Held 2007, p.254). Ultimately, the objective is

to forge an accountable and responsive politics at local and national levels alongside the establishment of representative and deliberative assemblies in the wider global order; that is, a political order of transparent and democratic cities and nations as well as of regions and global networks within an overarching framework of social justice (Held 207, pp.254-255).

Globalization can here be helpful to the goals of cosmopolitan democracy. Although in other ways it is a stressor for states, nevertheless, as Archibugi $(2011$, p.3) suggests, it offers innovations that can foster aspects of cosmopolitan democracy:

New information and communication technologies are opening the gates to a genuine global public sphere, and it has become technically feasible for communities living in remote parts of the world to take part in the same deliberative process. Such deliberations are already happening in elite circles such as professional associations. But they can also involve the global demos as a whole, especially when issues that affect the destiny of all humanity (such as environmental and security issues) are at stake.

Thus, for Archibugi, (2008, p.5) the most critical element of operationalizing and advancing cosmopolitan democracy is the ability to extend democracy beyond borders, to "create new forms of management of public matters that are also open toward the exterior and to include in the decision-making process those who are affected by certain decisions."

\subsection{Environmental justice}

Environmental justice has its origins in two main sources, and emerged as both a public policy issue and a social movement from a confluence of the two. The first source is the legacy of the civil rights movement in the United States whose demands for equal recognition and protection under the law for Afro-Americans from the 1950s-1970s was mirrored a couple of decades later by calls from marginalized communities for equal protection from environmental degradation. In this context, environmental justice started out as a series of specific, local issues and campaigns which linked communities and activists together into national organizing networks in the US and elsewhere (Agyeman \& Warner 2002, p.10). The common factor was the theme of equality, and the notion that "environmental quality is inextricably linked to that of human equality" (Agyeman 2008, p.752).

The second source for environmental justice is the concept of sustainable development deriving from the 1987 Report of the World Commission on Environment and Development (the Brundtland Report) and further developed in the 1992 Rio Earth 
Summit. It is captured in the definition famously used in the Brundtland Report (1987, p.43):

Sustainable development is development that meets the needs of the present without compromising the ability of future generations to meet their own needs. It contains within it two key concepts:

- the concept of 'needs', in particular the essential needs of the world's poor, to which overriding priority should be given; and

- the idea of limitations imposed by the state of technology and social organization on the environment's ability to meet present and future needs.

Equality and sustainable development, then, are at the core of environmental justice. However, dissatisfaction with the limitations of environmental justice, both in theory and praxis, has led scholars such as Julian Agyeman and David Schlosberg to refine the theory, or reinterpret key aspects of it. For Agyeman, the focus on environmental stewardship which he perceived in sustainable development praxis led to an overemphasis on inter-generational equity and an "equity deficit" in relation to intragenerational equity (Agyeman 2008, p.752). He has consequently developed the "Just Sustainability" paradigm which reinterprets sustainable development to restore the equity balance and firmly incorporate the need for intra-generational equity. Agyeman (Clarke \& Agyeman 2011, p.1777) has described the paradigm as one that

equally prioritises social inclusion, equity and justice in the delivery of sustainable development which it defines as: "the need to ensure a better quality of life for all, now and into the future, in a just and equitable manner, whilst living within the limits of supporting ecosystems."

The concept of justice is also central to David Schlosberg in his examination of the disjunctions between the way in which the social movement has articulated its demands for environmental justice globally and the inadequate conceptualisation of environmental justice theory. For Schlosberg, the key problem with environmental justice theory is the concentration on distributive justice. Drawing on theorists of social justice and difference, Schlosberg argues that focusing on models and procedures that aim to improve the distribution of justice ignores the factors that cause the "underlying poor distributions in the first place" (Schlosberg 2004, p.518). Thus, the "singular focus on justice as distribution, and only distribution, is not only limited in theory, but it cannot encompass the broad and diverse demands for justice made by the global environmental justice movement" (Schlosberg 2004, pp.536-537). For him, recognition (or respect) and participation are the crucial elements that are missing from theoretical accounts of environmental justice, and mean that such accounts are incomplete. Hence, he argues that there is a

direct link between a lack of respect and recognition and a decline in a person's membership and participation in the greater community, including the political and institutional order. If you are not recognised, you do not participate. In this respect, justice must focus on the political process as a way to address both the inequitable distribution of social goods and the conditions undermining social recognition (Schlosberg 2004, p.519).

A diverse and pluralistic discourse of justice is stressed by Schlosberg as necessary to understand and account for the demands of the environmental justice movement in its various forms and components. Indeed, Schlosberg and Carruthers (2010: 15) have argued that a capabilities approach to justice, such as those advanced by Amartya Sen 
(1999) and Martha Nussbaum (2000), "offers just such a broad and inclusive definition" when applied to indigenous environmental justice concerns.

For both Agyeman and Schlosberg, environmental justice is a theory that has developed out of grassroots activism, but which has experienced difficulties in coherently reconciling the conceptual and applied elements. This is a vulnerability that has been noted by critics who have suggested that environmental justice theory means everything and nothing. In this respect it differs from the accounts of cosmopolitan democracy offered by Held and Archibugi. For the latter scholars, the most problematic aspect of cosmopolitan democracy, and one that has similarly been the subject of considerable criticism, is how to operationalize a top-down theory and mobilize activism to achieve its goals. Although gains have been made in specific domains, such as in international law with the establishment of the International Criminal Court, implementing the theory remains an obstacle.

What is suggested in the next section, however, is that, despite these issues, cosmopolitan democracy and environmental justice theories offer opportunities for Global South states to use them in progressing and promoting common goals within the ATS.

\section{Cosmopolitan Democracy and Environmental Justice theories applied to the ATS}

Cosmopolitan democracy and environmental justice are new and still evolving theories that propound different and original ways of achieving social justice in the twenty-first century. In the ATS setting they present untried, but original and worthwhile, means for GS states to pursue common goals tied to their development and political agendas. Specifically, what these theories offer to decision-makers and leaders in the Global South are ways to confront and challenge hierarchic structures and exclusionary procedures within the ATS, and to gain for themselves and their populations entree', voice and a seat at the decision-making table.

The first thing to note is the importance for Global South states of reorienting their foreign policies to engage with Antarctica, acceding to the Antarctic Treaty 1959, and thereby joining the ATS. There are no financial costs to states for simply becoming signatories (Contracting Parties) to the Treaty, and the Treaty is open to all countries who wish to join. The importance of accession for GS states is the need to gain formal entry to the ATS, become a party to the operations of the system, and thus acquire the ability to work for reform of the system from within. As the 'Question of Antarctica' issue in the United Nations General Assembly demonstrated, taking challenges to the ATS to a forum such as the UN - although there were good reasons for doing so in the 1980s - allowed the Consultative Parties to mount a defence relying on their ability to portray non-ATS parties as ignorant and uninformed about Antarctica, and motivated by economic and political interests unrelated to the continent. Siting the locus of contestation in the UN permitted the Consultative Parties to be able to characterise the challenges made by non-parties as political theatre, deliberately played out before a world audience for the purpose of publicly embarrassing former colonial states and contemporary world powers for engaging in neo-colonialism and other repressive practices in contravention of the Charter of the United Nations. The presence of then-apartheid South Africa among the Consultative Parties group added substance to this characterisation.

Keeping GS challenges and reform efforts within the ATS would immediately refute the ability of Consultative Parties to undermine criticism from the GS by questioning their commitment to Antarctica. As fellow signatories to the Antarctic Treaty, and as states that are now formally engaging with Antarctica through their foreign policies, parties must be 
presumed to have a genuine and abiding interest in the continent. That signatory status would inherently add legitimacy to GS challenges to the ATS. The transformation of the status of Consultative Party South Africa from apartheid regime to multicultural democracy in the interim would also lend assistance to GS challenges, as it could not be used as a lightning rod to deflect attention from the critiques offered by GS states. In fact, South Africa's inclusion among the elite group might well be a positive bonus to newly acceding GS states as the country has shown itself to be capable of extraordinary transformation. That history of exclusion and oppression under apartheid, and successful transition to an inclusive democracy might be prevailed upon by new signatory GS states to persuade South Africa to show leadership among the Consultative Parties group in responding meaningfully to critiques which draw upon similar expressions of injustice.

Internal reform of the ATS, the route suggested here, may be beset by problems that can occur with such efforts. For instance: the time-consuming nature of the project may demoralize and frustrate supporters, provoking domestic political backlash for reform leaders among constituencies aggrieved by unrealized expectations; the gate-keepers and elite groups may prove resistant or unwilling to contemplate reform, or endlessly drag out reform negotiations without any real intention of change; gate-keepers and elite groups may threaten reformists and their interests in other areas, thereby imposing costs that might be considered too great to continue with the reform project; reform leaders may be bought off by promises or provision of personal gains in exchange for dropping the reform project, or de-prioritizing and downgrading its importance; elite groups may persuade third parties to intervene and bring pressure on the reformists to back down; elite groups may promote division among reformists by privileging one reform leader over another; reform leaders may lose the confidence of their supporters if they are unable to extract concessions within a reasonable time frame, and face internal challengers for their leadership position; or the reform group may splinter into different blocs promoting different solutions, thus losing cohesion, unity, and an important source of legitimacy.

Nevertheless, there are important gains that may be made by GS states if they are willing to pursue an internal reform project. From one perspective they have little to lose by proceeding with such a project. As non-participants, they are outsiders who are simply not in a position to facilitate change, influence key actors, or formally participate within the ATS. Nor have the Consultative Parties, to date, shown a willingness to spontaneously encourage reform of the ATS to more democratic and inclusionary structures, or to incorporate non-signatory GS perspectives into their deliberations. By contrast, the potential gains for GS states of pursuing internal reform, at the very least, include: participation in discussions about Antarctica's status and future; formation of a GS bloc of consultative parties able to lobby for their interests; being privy to discussions about key issues (ie, bio-prospecting in the Southern Ocean and Antarctic waters, regulation of Antarctic tourism and IUU fishing) that will have significant impact upon them; being able to exert influence in any deliberations prior to decision-making; gaining access to ATS information-sharing about Antarctica; raising awareness of GS developmental needs and promoting consciousness that GS states - particularly those with the lowest HDI indicators - must be part of any meaningful consultation or decision-making about Antarctic resource extraction in order to fulfil the Treaty promise of benefit to all of mankind.

How can cosmopolitan democracy and environmental justice theories be linked to this internal reform project? Essentially, their utility lies in providing an organized and holistic framework critiquing extant structures and procedures in the ATS, and positing alternatives that would fulfil GS needs and objectives. The valence of democracy, justice, equality, civil society and sustainable development in the two theories is that these are all concepts that can be employed to critique the ATS, and yet simultaneously speak to common GS political and developmental goals. 
Cosmopolitan democracy, for instance, is helpful in proselytizing an equivalence principle between decision-makers and decision-takers - the latter including all GS states, since Antarctica is agreed to be central to the global eco-system - which suggests greater transparency and accountability of the decision-takers. This has implications for consultative processes beyond the ATS and its Contracting/Consultative parties interface at ATCMs. It also has implications for reform of the Article IX(2) distinction between Contracting and Consultative parties.

Similarly, the use of cosmopolitan democracy theory suggests a much greater role for civil society and transnational citizens in the ATS, and the opening up of a global space in ATS discussions and deliberations for participation by those contributors. The observation can be made that, in fact, the superordinate importance given to science and scientific investigation in Antarctica from 1959 lends itself to such action as it accords paramountcy to a transnational activity. It can be argued that has already created cosmopolitan democracy traction by establishing an embryonic transnational citizenry of sorts - an epistemic community in policy terms - of Antarctic scientists.

Environmental justice is equally helpful to a reform project in identifying and interrogating ATS hierarchies and inequalities. The theory's emphasis on equality and justice deconstructs the historical foundations of the Antarctic Treaty and its membership, allowing questions to be asked about the western and colonial membership basis of the Treaty, and the privileging of founding signatories by automatically granting them Consultative Party status. It also reveals the inequitable situation for GS signatory states in gaining Consultative Party status, given that only three (South Africa, China, India) are part of the elite decision-making group - and South Africa gained its status as a founding signatory - despite the Treaty being in existence for over fifty years. Importantly, using the notion of recognition and participation argued by Schlosberg as an integral part of justice, permits reformists to investigate the lack of these elements for GS states, and to argue this as an ongoing denial that deprives them of the ability to gain social justice and true self determination.

From a reform perspective, environmental justice theory has application to the idea of Antarctica as a commons, and so supports both the Treaty's Article IV 'freezing' of all sovereign claims to the continent and the preamble injunction about Antarctica's special status being used for the "progress of all mankind". While many GS states would undoubtedly like to revisit the Common Heritage of Mankind argument and its applicability to Antarctica, the Treaty's placing in abeyance of claims to the continent does not preclude the revival of those claims should the Treaty cease to exist. In that situation there is little doubt that at least a number of the claimant states would pursue those claims vigorously, that other states (such as the USA and Russia) which have reserved the right to make a claim would do so, and that still other states that have risen in the power rankings since 1959 (such as China) would also make a bid for Antarctic territory. Moreover, even without the cessation of the Treaty freeing up states to claim parts of the continent, it is highly likely that the claimant states would oppose a Common Heritage of Mankind designation, just as they did when the issue was debated in the United Nations in the 1980s. Even as a preventative or defensive measure, therefore, using environmental justice to reinforce the idea of the continent as a global commons would at least earn GS states a putative right to be consulted, preferably as ATS signatories but also as affected decision-takers in the event of Antarctic Treaty cessation, about decisions having a fundamental impact on Antarctica.

So far, the theories application has focused on GS political goals of inclusion and democratic participation, and the barriers to these in the ATS. But there are also common GS developmental goals that the theories can be applied to. Environmental justice and 
the emergent just sustainability paradigm also offer opportunities to foster these goals within the ATS. By pressing the need to meet the justice and equity requirements of GS states as a necessary part of "the progress of all mankind", reformists could advance an agenda of development generated in part from Antarctic resource extraction. Bioprospecting presents the most obvious example of the way that GS countries could channel money drawn from resource extraction into capital funding of major development projects - assuming that they were strongly represented at any negotiations, and were able to gain the same kinds of protections as with The Area in the United Nations Convention on the Law of the Sea. If so, it would give them an invaluable mechanism for beginning to remedy their pre-existing 'poor distributions'. The goal of intra-generational equity would have a real chance of being achieved if development funding could be catalysed through this mechanism.

Finally, the concept of sustainable development embedded in environmental justice should serve to reassure gate-keepers and elites that the GS reform project is not about opening the gates to a gold rush in Antarctica, but about using Antarctic resources responsibly and within sustainable limits to achieve intra-generational equity, and still with the needs of future generations squarely in mind.

\section{Results and conclusions}

As the previous section has shown, cosmopolitan democracy and environmental justice theories can be applied in the ATS by GS states within a reform project, and these theories offer advantages for the states in pursuing common political and developmental goals. The 'start-up' costs for this endeavour are negligible. There is no financial barrier to signing the Antarctic Treaty, and minimal financial outlay needed for GS states to participate in the ATS as Contracting Parties. The greatest resources required are political will, determination, and patience.

The potential benefits, however, are enormous. Even as a singular event, achieving a voice for GS states and an acknowledged presence in Antarctic decision-making fora would be valuable. Recognition (or respect) and participation are corollaries of the pursuit of equality and social justice, and that is the possible benefit that GS states may realise if reform of the ATS in line with cosmopolitan democracy and environmental justice theories is realised. Those are goals whose worth cannot be quantified.

What can also be gained for GS states is the opportunity to be part of what will certainly be difficult and contentious future discussions about resource extraction issues, such as Antarctic bio-prospecting, not as petitioners, but as insiders with clearly articulated needs and wants - ideally, backed up with a bloc presence in the ATS and with champions in the Consultative Parties group. If GS states were able to achieve reform of the Article IX(2) barrier to membership of that group, then so much the better for their chances of establishing equitable benefit-sharing schemes that could be used to finance large-scale development programmes and create better life opportunities for millions of people in affected states.

\section{Recommendations}

What sections 6 and 7 suggest, and what is strongly recommended here, is that GS states that are not party to the ATS should reorient their foreign policies to incorporate goals of engagement with Antarctica and accession to the Antarctic Treaty. Although GS states face serious local problems that demand their immediate attention, there are long-term benefits for the states in joining the ATS in numbers and initiating an internal reform project. While efforts to reform the ATS through the UN largely failed in the 1980s, the development of recent theories of cosmopolitan democracy and environmental justice, 
coupled with the rise of commercial interests in Antarctica, offer opportunities for GS states to press for changes to the ATS that would help enable realisation of common political and developmental goals. In the second decade of the $21^{\text {st }}$ century, the time may now be ripe for the world's poorest countries to demand just transition from a system founded on an imperial construct to one that is truly equitable, just and democratic.

\section{References}

Agyeman, J \& Warner, K 2002, 'Putting 'just sustainability' into place: From paradigm to practice', Policy and Management Review, vol.2, no.1, pp.8-40.

Agyeman, J 2008, 'Toward a 'just' sustainability?', Continuum: Journal of Media \& Cultural Studies, vol.22, no.6, pp.751-756.

Antarctic Treaty Washington 1959, 402 UNTS 196172.

Antarctic Treaty Secretariat 2013, 'Antarctic Treaty: Parties', viewed 12 February 2013, $<$ http://www.ats.aq/devAS/ats parties.aspx?lang=e >.

Archibugi, D 2003, 'Demos and cosmopolis' in Debating cosmopolitics, ed D. Archibugi, Verso, London \& New York, pp.257-272.

Archibugi, D 2008, The global commonwealth of citizens, Princeton University Press, New Jersey.

Archibugi, D 2011, 'Cosmopolitan democracy: A restatement', Social Sciences Research Network, viewed 12 April 2012, <http://ssrn.com/abstract=1460678>.

Beck, P 1986, The international politics of Antarctica, St Martin's Press, New York.

Berkman, P 2002, Science into policy: Global lessons from Antarctica, Academic Press, San Diego.

Bulkeley, R 2010, 'The political origins of the Antarctic Treaty', Polar Record, vol.46, iss.1, pp.9-11.

Buck, S 1998, The Global Commons, Island Press, Washington.

Chaturvedi, S 1996, The polar regions: A political geography, John Wiley \& Sons, Chichester.

Clarke, L \& Agyeman, J 2011, 'Shifting the balance in environmental governance: Ethnicity, environmental citizenship and discourses of responsibility, Antipode, vol.43, no.5, pp.1773-1800.

Dodds, K 2011, 'Sovereignty watch: Claimant states, resources and territory in contemporary Antarctica', Polar Record, pp.231-243.

Dodds, K 2012, The Antarctic: A very short introduction, Oxford University Press, Oxford.

Elzinga, A 2013, 'Rallying around a flag? Scientific internationalism in word and deed' in The emerging politics of Antarctica, ed AM Brady, Routledge, London \& New York, pp.193-219.

Grob, J 2007, 'Antarctica's frozen territorial claims: A meltdown proposal' Boston College International and Comparative Law Review, vol.30, iss.2, pp.461-484.

Hemmings, A 2007, 'Globalisation's cold genius and the ending of Antarctic isolation' in Looking south: Australia's Antarctic agenda, Federation Press, Sydney, pp.176-190.

Held, D 1998, 'Democracy and globalization' in Re-imaging political community, eds. D Archibugi, D Held \& M Kohler, Stanford University Press, California, pp.11-27.

Held, D 2007, 'Reframing global governance: apocalypse soon or reform!' in Globalization theory, eds D Held \& A McGrew, Polity Press, Cambridge, pp. 240-260.

Heywood, A 2011, Global politics, Palgrave Macmillan, Basingstoke.

International Association of Antarctica Tour Operators (IAATO) 2012, '2011-2012 Tourists by nationality: Landed', viewed 18 February 2013 , $<$ http://iaato.org/documents/10157/91866/touristsbynationality landed.pdf $>$.

Jabour J, 2013 'Biological prospecting in the Antarctic: Fair game?' in The emerging politics of Antarctica, ed AM Brady, Routledge, London \& New York, pp.242-257.

Linklater, A 1998, 'Citizenship and sovereignty' in Globalization theory, eds D. Archibugi, D. Held \& M. Kohler, Stanford University Press, California, pp.113-137. 
Linklater, A 2008, 'Globalization and the Transformation of Political Community' in The globalization of world politics, $4^{\text {th }}$ edn, eds J Baylis, S Smith, \& P Owens, pp.542558.

McGrew, A 2008, 'Globalization and Global Politics' in The globalization of world politics, $4^{\text {th }}$ edn, eds J Baylis, S Smith \& P Owens, pp.14-33.

Nussbaum, M 2000, Women and human development: The capabilities approach, Oxford University Press, Oxford.

Pew Charitable Trusts 2013, Environmental initiatives: Global campaign to end illegal fishing, viewed 14 February 2013, $<$ http://www.pewenvironment.org/campaigns/global-campaign-to-end-illegalfishing/id/8589941944>.

Rayfuse, R 2008, 'Warm waters and cold shoulders: Jostling for jurisdiction in polar oceans', UNSW Law Research Paper No.2008-56, viewed 1 February 2013, $<$ http://law.bepress.com/cgi/viewcontent.cgi?article=1131\&context=unswwpsflrps08>.

Protocol on Environmental Protection to the Antarctic Treaty 1991, 30 ILM 1461.

Rothwell, D \& Scott, S 2007, 'Flexing Australian sovereignty in Antarctica: Pushing Antarctic Treaty limits in the national interest?' in Looking south: Australia's Antarctic agenda, Federation Press, Sydney, pp.7-20.

Schlosberg, D 2004, 'Reconceiving environmental justice: Global movements and political theories', Environmental Politics, vol.13, no.3, pp.517-540.

Schlosberg, D \& Carruthers, D 2010, 'Indigenous struggles, environmental justice, and community capabilities', Global Environmental Politics, vol.10, no.4, pp.12-35.

Scott S (2011), 'Ingenious and innocuous? Article IX of the Antarctic Treaty as imperialism, The Polar Journal, vol.1, no.1, pp.51-62.

Sen, A 1999, Development as freedom, Anchor, New York.

Triggs, G 1987, 'The United Nations in Antarctica? A watching brief', in The Antarctic Treaty regime: Law, environment and resources, ed G Triggs, Cambridge University Press, Cambridge, pp.229-233.

United Nations Development Programme (UNDP) 2011, Human development report 2011: Sustainability and equity - A better future for all, United Nations, New York.

United Nations 2000, (UNGAR 2000) General Assembly Resolution 55/2, United Nations Millennium Declaration.

United Nations 2010, (UNGAR 2010) General Assembly Resolution 65/1, Keeping the promise: united to achieve the Millennium Development Goals.

Verbitsky, J 2012, 'Antarctic tourism management and regulation: The need for change,' Polar Record, doirt:10.1017/S003224741200071X.

Vogler, J 1995, The global commons: A regime analysis, John Wiley \& Sons, Chichester.

World Commission on Environment and Development 1987, Our common future, Oxford University Press, Oxford. 